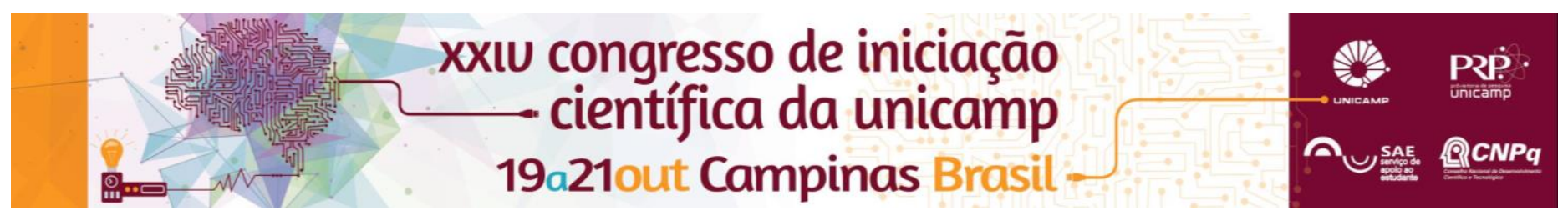

\title{
Tópicos em Álgebra Linear: Sistemas Lineares e Quadrados Mínimos
}

\author{
Alfredo Vitorino*, Márcia Aparecida Gomes Ruggiero.
}

\section{Resumo}

Neste projeto estudamos métodos de fatoração matricial, mais precisamente: a fatoração LU, a fatoração de Cholesky e a fatoração ortogonal, que são empregados na resolução de sistemas lineares. As duas últimas fatorações também são ferramentas importantes no problema de ajuste de curvas pelo método de Quadrados Mínimos, que surge em diversas aplicações, como por exemplo, o uso dos dados de recenseamentos para a previsão populacional.

\section{Palavras-chave:}

Álgebra Linear, Sistemas Lineares, Quadrados Mínimos.

\section{Introdução}

A Álgebra Linear é essencial para diversas áreas do conhecimento. Alguns tópicos têm maior destaque em aplicações, como a resolução de sistemas lineares e o método dos Quadrados Mínimos.

$\mathrm{Na}$ resolução de sistemas lineares, um processo de fatoração é útil, pois consiste em decompor a matriz dos coeficientes em um produto de dois ou mais fatores e, em seguida, resolver uma sequência de sistemas mais simples, para no final obter a solução do original. Entretanto, quando o sistema envolve mais equações do que incógnitas, teremos um sistema possivelmente sem solução exata. Nestes casos, obtemos a denominada solução de Quadrados Mínimos. Neste trabalho, estudamos de modo introdutório esta solução, bem como dois processos para obtê-la, através da fatoração de Cholesky e por meio da fatoração ortogonal.

O objetivo principal é motivar o estudo de conceitos fundamentais da disciplina, com ênfase em tópicos importantes para problemas práticos. Além disso, organizamos um material didático amplo, que foi construído com exemplos e aplicações, e está disponível em uma página na internet.

\section{Resultados e Discussão}

Apoiados na literatura e em softwares, como o MatLab, analisamos os métodos de fatoração matricial para a resolução de sistemas lineares.

A fatoração LU baseia-se na eliminação Gaussiana, que consiste em aplicar, convenientemente, operações elementares sobre as equações do sistema linear. Esta fatoração é bastante utilizada, porém requer estratégias de pivoteamento.

A fatoração de Cholesky é mais rápida, porém só pode ser utilizada em matrizes simétricas, definidas positivas.

A fatoração ortogonal consiste em decompor a matriz em um produto $Q R$, onde $Q$ é uma matriz ortogonal e $\mathrm{R}$ é triangular superior. Consideramos a obtenção destes fatores através do processo de GramSchmidt e por Transformações de Householder. Esta fatoração é vantajosa por ser mais estável numericamente, devido à ortogonalidade da matriz $Q$.
Além disso, acrescentamos o tema determinante, pois suas propriedades são fundamentais em resultados teóricos, e também com o objetivo de ampliar o material didático elaborado.

Em diversas situações, a solução de um problema pode levar a um sistema linear inconsistente. Surge então a necessidade de obtermos uma solução que satisfaça de modo aproximado o conjunto de equações lineares. $O$ conceito de aproximação adotado é a minimização da soma de quadrados dos resíduos, e temos então a denominada solução de Quadrados Mínimos. Uma das aplicações mais importantes deste problema é o ajuste de curvas: dado um conjunto de pontos obtidos experimentalmente, buscamos encontrar uma função cujo gráfico melhor se ajusta a estes pontos.

Estudamos alguns problemas práticos nesta área, como por exemplo:

previsão populacional de um local em determinado ano, através da análise de funções de ajuste aos dados de recenseamentos;

estimativa do número de acidentes com veículos no futuro, através de uma análise de série temporal; determinação de uma relação aproximada entre a resistência à compressão do concreto e a razão água/cimento, e outras aplicações à engenharia.

\section{Conclusões}

A proposta da pesquisa foi cumprida e todo o material elaborado, com exemplos, imagens e aplicações, está disponível em uma página na internet, podendo ser acessado por todos.

\section{Agradecimentos}

À profa. Dra. Márcia Aparecida Gomes Ruggiero, pela orientação e confiança.

À minha família, pelo apoio e incentivo.

Ao CNPq, por ter financiado este projeto.

\footnotetext{
${ }^{1}$ Franco, N. B. Cálculo Numérico. Pearson Education, $1^{\mathrm{a}}$ edição, 2007.

2 Ruggiero, M. A. G. e Lopes, V. L. da R. Cálculo Numérico - Aspectos Teóricos e Computacionais. Makron Books, $2^{\mathrm{a}}$ edição, 1996.

${ }^{3}$ Watkins, D. S. Fundamentals of Matrix Computations. John Wiley \& Sons, 3rd edition, 2002.
} 